\title{
Discussion on the Improvement of the Rural Old Age Service System by Physical Endowment
}

\author{
Keqing Sheng \\ School of Literature, Law and Economics \\ Wuhan University of Science and Technology \\ Wuhan, China
}

\author{
Wanlu Yuan \\ School of Literature, Law and Economics \\ Wuhan University of Science and Technology \\ Wuhan, China
}

\begin{abstract}
A cardinal number of a population is big, and the aging of said population is speeding up rapidly in China. The traditional family supporting model has been challenged. Based on the research method of documentation, interviews, field analysis, and mathematical statistics, the elderly endowment situation of Yichang west rural was taking as the research object in this paper. The results showed that the rural empty-nesters quantity is high. From institutional level, because of the lace of unified operative standard, elderly life quality is low at this endowment mode. On the basis of the traditional pattern of old-age support and the new model, physical endowment was needed to be introduced to rural in order to improve the elderly life satisfaction. First, the elderly can increase happiness by participating in national fitness. Secondly, the rural government purchase of public endowment services is an effective way to improve the public sports purchase system, and it also is an important measure to promote sustainable development of old-age service.
\end{abstract}

Keywords-Rural areas; Sports endowment; Public service

\section{INTRODUCTION}

"The 2016 statistics bulletin of the national economy and social development" points out that China has entered an advanced stage of ageing society. At of the end of 2016, there were 150 million Chinese over 65, accounting for $10.8 \%$ of the population, according to the National Census Bureau. Old people over 65 account for more than $7 \%$ of the population which indicate that China will enter an advanced stage of ageing among developing countries. The development of rural elderly population during 2011-2015 are shown below:

TABLE I. STATISTICS FOR THE POPULATION OF VILlages

\begin{tabular}{crrrrr}
\hline Index & $\mathbf{2 0 1 1}$ & $\mathbf{2 0 1 2}$ & $\mathbf{2 0 1 3}$ & $\mathbf{2 0 1 4}$ & $\mathbf{2 0 1 5}$ \\
\hline $\begin{array}{c}\text { Aging population } \\
\begin{array}{c}\text { (Million) } \\
\text { Total population } \\
\quad \text { (Million) }\end{array}\end{array}$ & 65656 & 64222 & 62961 & 61866 & 60346 \\
$\begin{array}{c}\text { Dependency } \\
\text { Ratio } \\
\text { (percent) }\end{array}$ & 12.3 & 12.7 & 13.1 & 13.7 & 14.3 \\
\hline
\end{tabular}

From "Table I", the population of villages decreased slowly, but the rural elderly population dependency ratio presents a stairs type to continuously rise which brings the threat to social security system. By the end of 2015 , the elderly population rised to 630 million. The rural elderly population dependency ratio is $14.3 \%, 2 \%$ higher than 2011 . As the change of the family structure, tremendous pressure presented to young people which influence the rural family endowment. The traditional family endowment can merely meet the lowest need: survival needs, according to Maslow's hierarchy theory of needs. Nowadays, with the development of social economy, the need of self-actualization is increasing. Furthermore, physical endowment link up with the spirit demand of the high level. The elderly participate in sports activities to form a sense of belonging, and based on the physical and mental characteristics of the elderly to sports and sports public services to improve the elderly happiness index of old-age way, meets the elderly high-level spiritual needs level endowment. Research on physical endowment, scholars at home and abroad mainly focused on the current situation, path analysis to aged sport's promotion, the present situation of the public gymnastic and stadium facility, and physical endowment feasibility in urban areas. These form the angle of social P. E.; the paper deals with development of physical endowment in rural areas and the way to improve the old-age service system.

\section{AGED RETIREMENT IN THE VILLAGE}

\section{A. Rural Endowment Situation Analysis}

Villages, namely rural area or rural settlement, refers to the areas where people live in order to meet their needs in production and livelihood. Village endowment means to provide lodging and related comprehensive services for rural aged people. Beiya village was taken as an example, which is located in the yangtze plain on the outskirts of Yichang in Hubei Province. A primary economic source is the tourist economy, whereas the location of scenic spot can't form a cluster effect. There are seven villagers groups in the village. By the end of 2016, the rural population was 1200. Old people over 65 years old were 102. Among them, the choice of family endowment is 85 , while the rest of 17 rely on social insurance endowment. Endowment was provided 100 Yuan monthly by village councils at subsidized levels. The reference is women over the age of 55, man over the age of 60 .

As a result, it's obvious that Beiya village focuses on family and social old-age endowment insurance two models. Generally, there are three kinds of rural endowment way. The first is family endowment. It reflects the 
intergenerational support functions; Children cannot be relieved from supporting their parents. The second is community endowment. The organic whole was connected by a simpler society, while local governments take the obligation of endowment infrastructure; Third is the social endowment insurance endowment. That is an effective way to guarantee their basic life after retiring.

\section{B. Traditional Endowment Model}

Traditional endowment model is referred to as family endowment. The blood is a link to the parent-child love which traditional Chinese family has in the elderly support. There are three kinds of the situation: one is family endowment. It can provide security, improve comfort, and provide spiritual consolation for the elderly. Then, the elderly get aged endowment insurance. According to the relevant provisions of the "Land Management Law", Article 47 Land expropriated is compensated for on the basis of its original purpose of use. In this way, the government increases their social account to compensate. Last is that institutions support endowment. From the perspective of social security, traditional endowment patterns include family endowment, social endowment insurance endowment and institutions supported endowment. It can only meet the basic needs: survival.

\section{Existing Problems in the Traditional Endowment Model}

Research has shown that the function of family supporting for the elderly is weakening, which increased young people's life pressure. Family endowment set high time continuity requirement. It was affected by the elderly health situation which may increase family economic burden. With the development of new rural endowment insurance, the coverage of social security expanded, and the social security is strengthened. However, the elderly members of the community can meet just the basic needs of life; it still needs to develop and meet a high-level need of selfactualization. At present, the government encourages old-age care institutions held by organizations but lack monitoring them. For one thing, living in institution can hardly maintain for huge expenses. For another, it can only guarantee the basic life level, far from the spiritual life needs. Maslow's theory of needs of the people is divided into three levels: survival needs, demand and growing demand relationship. Traditional endowment only meets the first level: survival needs. Their living standards improves; old people need social recognition and spiritual support. Meanwhile, they can be appropriate to participate in social management to realize personal value.

\section{PHYSICAL ENDOWMENT-THE NEW WAY}

\section{A. Physical Endowment}

Sports endowment is the elderly participating in sports activities to form a sense of belonging, and, based on the physical and mental characteristics of the elderly to sports and sports public services to improve the elderly happiness index of old-age way, the goal is to meet the elderly highlevel spiritual needs level endowment. Our country rural aged population development trend shows a large population base, a high speed of increasing proportion of "empty nest elderly". This is a rapid development of aging population. It's urgent that we improve the healthy of the elderly through the science physical training method. An ageing population is not equal to the economic development and the welldistributed. With the concept of the national fitness promotion, many old people treat it as "navigator". They exercise more to improve health condition.

Sports endowment teaches them health knowledge, health care skills and promotes the development of the elderly health. There are differences for exercise preference among the aged from the perspective of physical endowment practicability. The government needs to expand the number of sport types. At present, the rural elderly demand for oldage changed, from the physical health needs to transition to self-worth in order to achieve the needs of sports endowment. On February 28, 2017, the 13th Five Year Plan and its National old age programs development and Endowment system construction plan were promulgated by the state council. The national fitness program was emphasized. It was put forward that, in 2020, the elderly sports organizations at the grass-roots level should be built up in $90 \%$ of the streets and villages and towns. The elderly realized that, through the ways of physical exercise, physical quality could be enhanced, and physical health could be strengthened. For the launch dynamics of the countries to increase the public sports hardware infrastructure that suitable for the elderly fitness, the development of rural areas lack slightly.

\section{B. The Feasibility of Sports Endowment}

Sports endowment expanded the function of endowment industry and was helpful for the endowment industry to get local government support and social organization's actively participate, improving the market access permission mechanism. It was a kind of new endowment way with high feasibility to carry out the activities to entertainment body and mind, to provide medical and health services and to promote the health care knowledge collectively in the elderly. Guide the rural elderly people to participate in sports fitness activities so they can realize healthy aging. Harmonious ageing was "aids to navigation" to improve their life quality. The aim at how to develop sports endowment some scholars put forward cultivating sports talent to work in endowment industry. The key is to strengthen the construction of endowment service system and sports infrastructure with the local governments' auxiliary policy support. Firstly, the elderly can improve the body function by participating in sports activities. Secondly, strengthen the communication between the elderly can ease the loneliness. Finally, the institution that the government buys public sports endowment in rural areas should be implemented. Synchronous development of the rural and the urban endowment institution should be promoted so as to improve the life satisfaction for the rural elderly.

According to the statistics, among the infrastructure of rural sports activities, $67.01 \%$ were organized by the village committee, $30.93 \%$ were funded by local governments and the other $2.06 \%$ were constructed by social organizations. The health industry development speed up in rural areas, 
more public sports infrastructure were established, the elderly contact appropriate physical activity, and the enthusiasm of sports activities improved. Upgrading health industry to provide the source power for the elderly to participate in physical exercise was on the agenda in "Health China 2030 Program". For the elderly, body functions degenerate gradually, thus, they can promote physical fitness when increasing physical exercise frequency.

\section{IMPLEMENT SUGGESTIONS OF RURAL PHYSICAL ENDOWMENT}

\section{A. Government Purchase of Public Endowment Services}

At present, under the background of government transition, building a service-oriented government has become the only path to a new stage. "The national basic public service system construction plan of 13th Five Year Plan" clearly pointed out that, to solve the problem of "terminal plug", upper level optimization should be made from the point of the basic public service supply. "The plan" points out that government purchase of public services can make endowment service system perfect to cope with the aging problem According to the survey, the view of the public service research was mainly focused on the sports public services and the aged public service. There was little academic research on the government purchase of public services. For the research of government purchase of public services, some scholars pointed out that the buyer should be diversified from the only buyer of the government to multiple subjects. The public service purchase path and sports public service accountability mechanism could be introduced to improve the purchasing efficiency for the research of government purchase of public services. Some scholars put forward that the principal-agent relationship between the government and organizations should be formed, the government was responsible for the sports endowment service funding and social organizations or individuals was responsible for the management. The government purchase of endowment service can provide the elderly the necessary low-level service such as survival and health. The government purchase of sports services can satisfy their high-level self-perfection needs. When these were combined, the transformation of the lower level requirements to the high-level requirements could be realized. This article hold the point that the government purchase of public endowment service means the public sports service aiming at improving the elderly endowment quality that the endowment services was paid by the government and managed by sports social organizations or individuals. A contractual relationship was formed between the government and social organizations.

From the macro level, some rules and laws should be established by to improve the standardization sports endowment service and to promote the purchase program to form system and avoid formalized sports endowment service project. Public sports endowment service belongs to quasipublic service, supervision should be strengthened, and the performance evaluation index system should be established. The performance evaluation index can be set as four sides; there are grounds and facilities (the grounds and facilities jointly built by government public capital and social organization), expense expenditures, the administrators staffing and service evaluation standard. In the government purchase process of public endowment, duties were transferred between the government and social organizations under a signed agreement to provide funding support for the sports endowment service. The breadth and depth government purchase of public endowment service need to be extended, the specific purchase content can be sports science, sports health care and fitness exercises. At the same time, the sports endowment e-government should be implemented. The physical ability characteristics and physical quality of the elderly should be considered when local governments provide sports endowment service. The potential to actively participate in sports activities of old people should be developed to improve their sports cognitive ability.

\section{B. Social Groups Rich Sports Categories}

Social organization is an important part of contemporary Chinese political life. It refers to an integrated body constitute by a group of people that joint up or organized with a certain economic base and superstructure for a common purpose, interest or entertainment in "several opinions about speed up the development of endowment services" issued by the state council. It was mentioned that a social group as an organization should gradually become the main body of sports endowment service. Social forces joining the endowment services would be helpful to build the environment of equal participation and fair competition and to extend the breadth of endowment service. Social organizations can boost the enthusiasm of the rural elderly people to participate in sports activities through the distribution of sports science, sports health care knowledge, and the knowledge of fitness that cooperated with the local government. The elderly can expand their horizon and communicate emotions with their peers when participating in activities. Then, their life could be enriched. On the one hand, social organization can help the elderly get access to different types of sports cultural services, and that can meet their variety demand. On the other hand, the government can supervise the management of social organization to promote the systematic development of sports endowment.

\section{Rural Village Committees Play a Guiding Role}

In rural areas, country resources, including the hardware and the software, should be fully relied on promoting the sports endowment service. According to the diversed and specialized requirements of the different elderly, the composition of sports activities should be diversed. Rural responsible should fully improve the enthusiasm of the elderly as far as possible to participate in group activities. For rural areas, a long history of ancient culture has brought some regional culture characteristics. Thus, cultural exchange activities with local characteristics can be processed. Make appropriate classification for the elderly based on different sports activities hobbies, and organize targeted sports cultural activities suitable for the elderly. The organizers of the countryside requires guidance and training. One can draw lessons from expert advice at the same time and promote the development of the rural elderly health in good condition. In addition, the relevant staff should have 
service consciousness promoting the sports endowment in rural areas. As a service provider, a good professional spirit and the enthusiasm to service for the elderly were needed. Improving their communication and organizational ability should be set as the goal through enhancing their own quality and increasing their professional knowledge. To guide the elderly sports activities, make the residents love sports, enhance physical fitness, and ultimately achieve the goal of physical and mental pleasure.

\section{CONCLUSION}

In this research, Yichang west village was taking as an example. The situation of Chinese rural endowment was analyzed. In general, the content of the traditional endowment model are family endowment, social insurance endowment and old-age institutions endowment. In this paper, the Maslow-Need-hierarchy theory was used to illustrate the elderly requirements hierarchy transition. Along with the social development, the elderly needs transferred from physiological survival to social respect. The traditional endowment model was being challenged, and sports endowment emerged. This endowment was with the function of improving elderly life stability and promoting the harmonious development of society. The government, social organizations and the village committee provide support for sports endowment to smooth develop.

\section{REFERENCES}

[1] Li Jian-guo. View of development of Chinese social sports in the three decades of reform and opening looking from the policy change [J]. Journal of Shanghai University of Sport, 2008, 32.

[2] Xia Cheng-qian. Tian Yu-pu. The sports transition development strategic focus changes of the People's Republic of China in recent 60 years [J]. Journal of Wuhan Institute of Physical Education, 2010, 44.

[3] Xiang Yun-hua. Present situation and the development countermeasures of urban community

[4] endowment in ethnic minority areas [J]. Journal of Yunnan Nationalities University, 2016, 03.

[5] Yao Hong. SWOT analysis and countermeasures for vigorously developing of the community endow ment service [J]. Guangxi Social Sciences, 2016,8.

[6] Wu Hai-xia. Review of academic seminar "Aging of population and endowment service industry development" [J]. Chinese Journal of Population Science, 2015, 121.

[7] Zhang Hong-sen. Path develop analysis of "Culturally supporting the aged" [J]. Journal of Liaoning Administration College, 2014,2.

[8] Li Wen-pu, Gong Zheng-wei. community sports culture endowment under the vision of "Culturally supporting the aged" [J]. Journal of Physical Education, 2014,21.

[9] Chang Bao-xing. The study on the aspiration of urban residents staying in nursing home [D]. Nanning: Guangxi University for Nationalities, 2012.

[10] Wang Pei-jun. Research of Chinese endowment based on the perspective of urban family structure change [D]. Shanghai: Shanghai University of Engineering Science, 2012.

[11] Guo Zai-jun, Zhou Ying-ling. The concerns of the sunset and happiness [J]. Journal of Hubei Normal University, 2012,1.

[12] Dai Fang-mei, Liu Ya-qi. Sports service supply and demand research on community home endowment service center, take Wuhan as an example [J]. Journal of Hubei Sports Science, 2016,11. 